\title{
EFFECT OF SINGLE-CONTACT SPARK PLUG ELECTRODE GAP ON COMPOSITION OF ENGINE EXHAUST EMISSIONS
}

\author{
Aivars Birkavs, Ruslans Smigins \\ Latvia University of Life Sciences and Technologies, Latvia \\ aivars.birkavs@1lu.lv, ruslans.smigins@1lu.lv
}

\begin{abstract}
The spark plug is an important part of the spark ignition (SI) engine, which, like other parts, outwears over time, but its outwear stages are often not felt at all in everyday use. For spark plugs, the manufacturer has specified the service life under specific operating conditions. However, if both gasoline and liquefied petroleum gas (LPG) are used as fuel in the spark ignition engine, the spark plugs outwear in a shorter period of time. This is due to differences in combustion temperatures, which are affected by the octane number of the fuel. The main sign of spark plug outwear is an increase in the gap between the electrodes, which is directly related to the combustion of the fuel mixture. Consequently, the composition of the exhaust gases also changes. Therefore, a study was performed on the effect of single-contact spark plug electrode spacing on the exhaust gas composition of SI engine running on gasoline and LPG. For the study, Peugeot 407SW vehicle was used, manufactured in 2006 and equipped with a 2.0-liter SI engine, which was additionally equipped with a gas fuelling system. Spark plugs BOSCH FR7NI332S were used in the experiment. The study found that hydrocarbons and carbon monoxide in exhaust gases can increase significantly, while carbon dioxide changes are inessential.
\end{abstract}

Keywords: car, electrodes, emissions, gap, spark plugs.

\section{Introduction}

Nowadays, spark ignition (SI) engines are used both in agriculture for the operation of various machines and as vehicles in the transport sector, especially in passenger cars. As the ignition process in SI is understood, its complexity can be influenced by different factors, where one of them is a spark plug.

Spark plugs are a small, but very important part of the SI engine design, which has to withstand very high temperatures and pressures and has to create a spark countless times over a period of time. During the last decades the basic spark plug design has been improved providing better ignition and longer life. Nowadays the numbers of spark plugs are quiet large, as they are classified according to several parameters: by the ignition type (contact or non-contact, battery, electric), injection system (carburettor, injector, single or multi-point injection), degree of engine forcing (compression levels and compression), according to the conditions of use of the engine and the fuel (deformed, forced, and equipped with a turbocharger, sports). Spark plugs are also classified by the thread diameter, length of the threaded part of the housing, o-ring, side electrode and some other parameters: by the thread pitch and diameter (M10x1; M12x1.25; M18x1.5), thread length (short $12 \mathrm{~mm}$, long $19 \mathrm{~mm}$, elongated $25 \mathrm{~mm}$ ), wrench size $(24 \mathrm{~mm} ; 22 \mathrm{~mm} ; 20.8 \mathrm{~mm} ; 19 \mathrm{~mm} ; 16 \mathrm{~mm}$ or $14 \mathrm{~mm}$ ), type of sealing (with flat compression ring or with cone), number of side electrodes (one or more).

Another important factor for spark plugs is a heat range, which shows the operating temperature of the spark plug and can be affected by the construction of the spark, including types of materials, the surface area of the plug, as also the length of the insulator. Based on the values, plugs are divided into three groups - "cold", "medium", "hot". There is no common scale of incandescent numbers, because almost every manufacturer has its own standards. Hot spark plugs are used in engines with low compression ratio and low fuel octane rating, because in such engines the temperature in the combustion chamber is not too high. Accordingly, cold spark plugs are used in engines with a high degree of compression and fuels with a high octane number. Medium spark plugs are the most common, because they occupy an average position between cold and hot.

An important factor in the operation of spark plugs is their service life. Most of today's spark plugs are made of alloy steel and their mechanical resource is 50-60 thousand $\mathrm{km}$. During this time, the central electrode burns out, the gap between the electrodes increases and the formation of spark ruptures begins [1]. To slow down the burning rate, a stronger metal is sprayed on the electrode surface or platinum solders and iridium electrodes are used in special cases. This makes production of spark plugs three to six times more expensive, but also increases a lifespan of up to 120 thousand $\mathrm{km}$.

Cars equipped with liquefied petroleum gas (LPG) use special spark plugs, the service life of which is the same as when driving with gasoline. Due to the higher octane number of LPG, it is more difficult 
to ignite, so a very strong spark is required. When the engine is running on LPG, the temperature in the combustion chamber is higher, so the spark plugs wear out faster. Special LPG spark plugs are much more expensive, because the electrode is made or coated with more durable metals such as silver, platinum, or gold. Installers of LPG systems offer the option of replacing conventional spark plugs twice as often as specified by the manufacturer in order to avoid uneven engine operation.

The spark plug gap is an important factor for the engine correct operation. Too wide gap may result in a misfire, while too narrow gap may result in a weak spark to ignite the fuel-air mixture. Besides that, the electrode gap can leave an impact on early formation of flame, which thereby can influence the engine performance [2], fuel efficiency and composition of exhaust emissions in such way causing air pollution [3]. Different researchers have studied the impact of the gap distance. Badawy [4] has studied effects of the spark plug electrode gap on the flame kernel development, engine performance and emissions working with a single cylinder gasoline direct injection engine. He concluded that the effect of the spark plug gap is dominant at lean and stoichiometric conditions, as also that maximum spark plug gap gives minimum hydrocarbon emissions, but higher NOx emissions. Bhaskar [5] has operated a single cylinder computerized spark ignited gasoline engine with different spark plug gaps, like 0.4, $0.5,0.6$ and 0.64 , at different injection timings and loads. He found that minimum coefficient of variation of the indicated mean effective pressure is for the spark gap of $0.6 \mathrm{~mm}$ at timing of 18 crank angle degrees before the top dead centre, and concluded that it increases the combustion process, and the drivability of the engine is smoother. Bas [6] has tested a single-cylinder, naturally aspirated, variable compression ratio spark ignition engine with 3 different types of spark plugs (copper, iridium and platinum) with $0.6 \mathrm{~mm}, 0.8 \mathrm{~mm}$ and $1 \mathrm{~mm}$ spark plug gaps. The tests have confirmed that increment of the spark plug gap increased the power output and reduced the fuel consumption. Best the results were obtained for platinum spark plug with a $1 \mathrm{~mm}$ spark plug gap and hydrogen blended gasoline combination. Another study [7] showed that the speed together with the iridium spark plug gap increase from $0.8 \mathrm{~mm}$ to $0.9 \mathrm{~mm}$ results in increase of vibration and noise, as also in hydrocarbon emissions. At the same time, Dave [8] concluded that in case of compressed natural gas (CNG) fuelled vehicles, which are retrofitted conversions from existing SI engines, modification of the spark plug gap is necessary to optimize the ignition system for better performance. The researcher has decided that spark plug increase could increase the torque and efficiency of CNG fuelled SI engine for lean mixture combustion.

The number of researches concerning the relationship of emissions to the spark plug gap is limited, therefore the aim of this research was to obtain better understanding how the spark plug gap can affect the most common engine emissions.

\section{Materials and methods}

Peugeut 407SW car was used in this research. This is 2006 release car with a 2.0 litre gasoline engine equipped with the fourth generation gas fuelling system (see Table 1). Tests were performed with used BOSCH FR7NI332S spark plugs (after 50 thous. km mileage).

Technical characteristics of the tested vehicle

Table 1

\begin{tabular}{|l|c|}
\hline \multicolumn{1}{|c|}{ Parameter } & Characteristics \\
\hline Engine type & EW10 A(RFJ) \\
\hline Number of cylinders & Inline 4 \\
\hline Fuel system & Multipoint fuel injection \\
\hline Bore x stroke, $\mathrm{mm}$ & $85 \mathrm{x} 88$ \\
\hline Number of valves & 16 \\
\hline Compression ratio & 10.8 \\
\hline Max. power & $103 \mathrm{~kW}$ at $6000 \mathrm{rpm}$ \\
\hline Max. torque & $200 \mathrm{Nm}$ at $4000 \mathrm{rpm}$ \\
\hline
\end{tabular}

Emission measuring was realized using a BOSCH BEA 350-EU (see Tab. 2) exhaust gas analyser, which allows to measure carbon monoxide $(\mathrm{CO})$, carbon dioxide $\left(\mathrm{CO}_{2}\right)$, hydrocarbons $(\mathrm{HC})$, lambda $(\lambda)$, oxygen $\left(\mathrm{O}_{2}\right)$. These components were measured and analysed during this research. 
Starting the test, the ignition coil block connector was disconnected. Then followed the unscrewing of the ignition coil bolts. The coils were fastened with two screws. When the screws were removed, the spool block was free and could be removed. The next step was removing the spark plugs. It required a $16 \mathrm{~mm}$ spark plug wrench or barrel with a rubber insert to hold the spark plug in the wrench.

For the removed spark plug the thickness gauge was used to set the required spark plug gap between the centre electrode and the ground electrode. When the gap was set, the spark plugs were screwed back in, then screwed in the ignition coil block and connected to the connector accordingly. When this was done, the exhaust gas analyser was connected. This took place at three points: 1) inserting a probe into the muffler, 2) inserting a temperature sensor in place of the oil dipstick, 3) attaching terminals to the battery terminals to determine the engine speed. When the sensors were connected, the diagnostic device was turned on and the vehicle data were entered.

Table 2

Analyzer measurement range and accuracy

\begin{tabular}{|l|l|l|}
\hline Component & Measurement range & Accuracy \\
\hline $\mathrm{CO}$ & $0.000-10.00 \%$ vol. & $0.001 \%$ vol. \\
\hline $\mathrm{CO}_{2}$ & $0.00-18.00 \%$ vol. & $0.01 \%$ vol. \\
\hline $\mathrm{HC}$ & $0-9999 \mathrm{ppm}$ vol. & $1 \mathrm{ppm}$ vol. \\
\hline $\mathrm{O}_{2}$ & $0.00-22.00 \%$ vol. & $0.01 \%$ vol. \\
\hline$\lambda$ & $0.500-9.999$ & 0.001 \\
\hline $\mathrm{NO}_{\mathrm{x}}$ & $0-5000 \mathrm{ppm}$ vol. & $<=1 \mathrm{ppm}$ vol. \\
\hline
\end{tabular}

As the car has two fuel systems, gasoline and gas injection, the first measurements were made during the gasoline injection operation, and only later - LPG. The analyser measured at the idling in the speed range of 800 to $3000 \mathrm{rpm}$. When the measurements have been made with gasoline, meeting the EN 228 standard, the system was switched to LPG. Three replications were performed for each measurement. The results of these replications were averaged to decrease the uncertainty and reported.

The spark plug gap was changed in the following order: $1.5 \mathrm{~mm}, 1.2 \mathrm{~mm}, 0.9 \mathrm{~mm}$ and $0.5 \mathrm{~mm}$. The settings were made using the BOSCH spark plug gap probe -0986600000 . The probe set is specially made for checking (measuring) spark plug gaps. It is used to control and adjust the gaps in the spark plugs of internal combustion engines. It consists of eleven test bars of different diameters: $0.3 \mathrm{~mm}$, $0.5 \mathrm{~mm}, 0.6 \mathrm{~mm}, 0.7 \mathrm{~mm}, 0.8 \mathrm{~mm}, 0.9 \mathrm{~mm}, 1 \mathrm{~mm}, 1.1 \mathrm{~mm}, 1.2 \mathrm{~mm}, 1.5 \mathrm{~mm}, 2 \mathrm{~mm}$.

\section{Results and discussion}

Measurements were made on the engine using both gasoline and LPG fuels. It was found that the gap between the spark plug electrodes plays an important role in the formation of toxic exhaust gases. If the engine was run on gasoline, the change in the gap between the electrodes affected the exhaust gas composition more than when the engine was run on LPG. The summarized results are presented in Fig. 1-5.

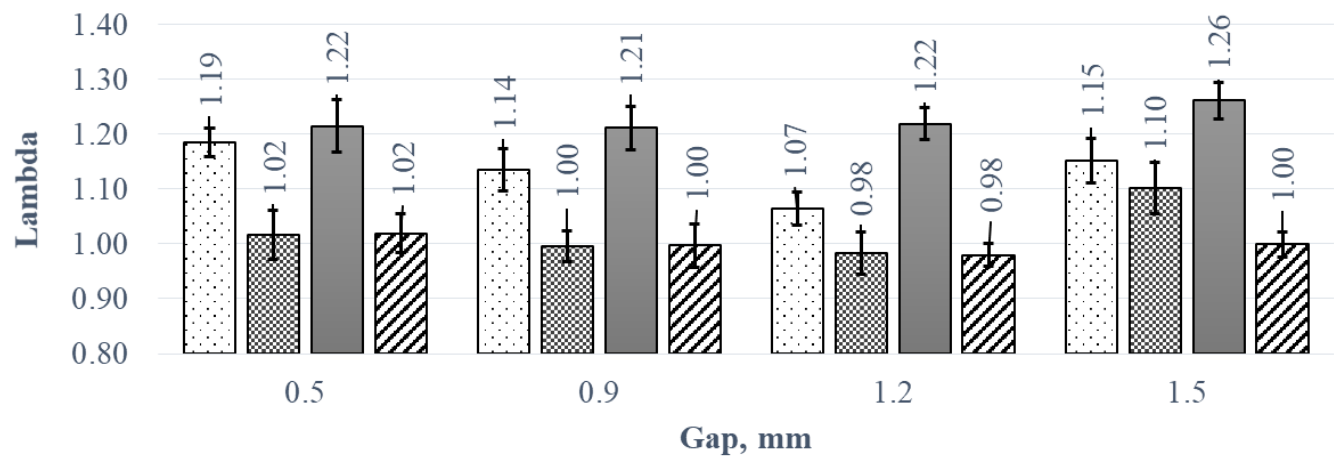

$\square$ Gasoline, $800 \mathrm{rpm}$ 因Gasoline, $3000 \mathrm{rpm}$ 口LPG, $800 \mathrm{rpm}$ 口LPG, $3000 \mathrm{rpm}$

Fig. 1. Lambda changes at certain gap sizes with different fuels and speeds 
In order to make it easier to understand how the amount of toxic emissions in the exhaust gas has changed, the variation in the amount of each measured exhaust gas component, as well as the changes in the coefficient $\lambda$ were distinguished in the data processing process. Figure 1 shows the changes detected by the lambda sensor. The highest lambda value was observed for the engine running on LPG, at idling $(800 \mathrm{rpm})$ with a set electrode gap of $1.5 \mathrm{~mm}$, but the lowest - when running on LPG at $3000 \mathrm{rpm}$ with a set electrode spacing of $1.2 \mathrm{~mm}$. It should be noted that all results are similar and impact of the gap is insignificant. The car manufacturer has set a $\lambda$ norm of $0.97-1.03$ with the engine running up to $3000 \mathrm{rpm}$. This is the case for all measurements with both gasoline and LPG.

Figure 2 shows the changes in $\mathrm{CO}$. The highest $\mathrm{CO}$ value was observed for the engine running on gasoline, at idling ( $800 \mathrm{rpm})$, at a gap of $1.5 \mathrm{~mm}$, but the lowest value was observed for the engine running on gasoline, at idling $(800 \mathrm{rpm})$, but at a gap of $0.9 \mathrm{~mm}$. The amount of $\mathrm{CO}$ has changed significantly based on the gap variation. It can be seen that for the engine running with a spark plug electrode gap of $0.9 \mathrm{~mm}$, all readings are very low. The car manufacturer has set a CO norm of $0.5 \%$ at idle (800 rpm) and $0.3 \%$ at increased idling (up to $3000 \mathrm{rpm}$ ). When the engine operated on LPG, this norm was achieved in all iterations of the experiment, but when it operated on gasoline, the norm was reached only with the set electrode spacing of 0.5 and $0.9 \mathrm{~mm}$.

The amount of $\mathrm{CO}$ is usually increased, if there is a rich fuel mixture, or if the fuel mixture does not burn properly. In this experiment it is clear that the increase in $\mathrm{CO}$ was influenced by the ignition factor, because no changes in lambda were observed. From the lambda values it can be concluded that the fuel mixture was stoichiometric, thus it can be concluded that no rich fuel mixture was used while $\mathrm{CO}$ still increased. Thus, it is the combustion process in the engine cylinder that has influenced the increase in $\mathrm{CO}$. This conclusion applies to both gasoline and gas engine operation.

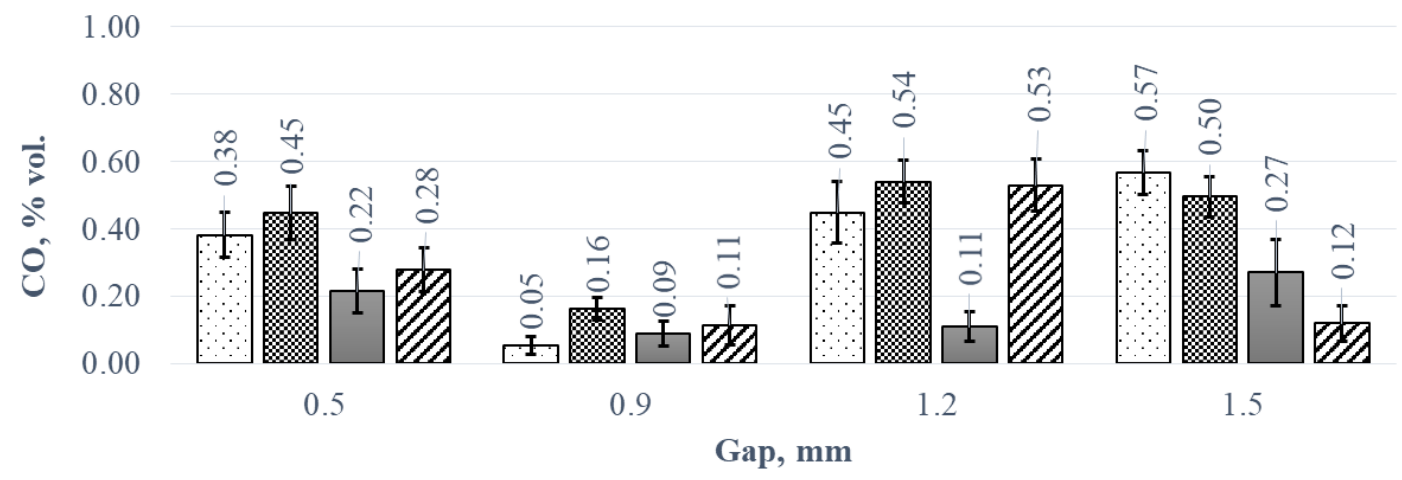

$\square$ Gasoline, $800 \mathrm{rpm} \quad \boldsymbol{\nabla}$ Gasoline, $3000 \mathrm{rpm} \quad \square \mathrm{LPG}, 800 \mathrm{rpm} \quad \boldsymbol{\square L P G}, 3000 \mathrm{rpm}$

\section{Fig. 2. CO changes at certain gap sizes with different fuels and speeds}

Figure 3 shows the changes in $\mathrm{CO} 2$. The highest amount of $\mathrm{CO}_{2}$ was detected when the engine operated with gasoline at increased idle speed $(3000 \mathrm{rpm})$, in all gap measurements, the lowest - when operated with LPG at increased idle speed (3000 rpm), at all gap settings. It can be seen that changing the electrode gap variations of $\mathrm{CO}_{2}$ is inessential. The car manufacturer has set a $\mathrm{CO}_{2}$ standard of 14.5$16 \%$ at idling.

All those measurements showed that the changes in $\mathrm{CO}_{2}$ do not exceed the norm set by the manufacturer. $\mathrm{CO}_{2}$ usually is closely connected with variations in fuel consumption - the more fuel consumed, the more $\mathrm{CO}_{2}$ will be observed during the tests. The insignificant changes observed in this experiment indicate that the fuel mixture ratio and fuel consumption have not changed greatly.

$\mathrm{HC}$ changes are shown in Fig. 4. The largest amount of $\mathrm{HC}$ was observed when the engine operated on gasoline at increased idle speed $(3000 \mathrm{rpm})$ with an electrode gap of $1.5 \mathrm{~mm}$. On the other hand, the smallest - when operated on gasoline at idle $(800 \mathrm{rpm})$ with a gap of $0.9 \mathrm{~mm}$. The results for the engine operated on LPG are similar in all replicates of the experiment. The car manufacturer has set an HC standard of $100 \mathrm{ppm}$ at idling. This norm has been achieved by the engine operating with a spark plug electrode spacing of $0.9 \mathrm{~mm}$ and $1.2 \mathrm{~mm}$, both with gasoline and LPG. 


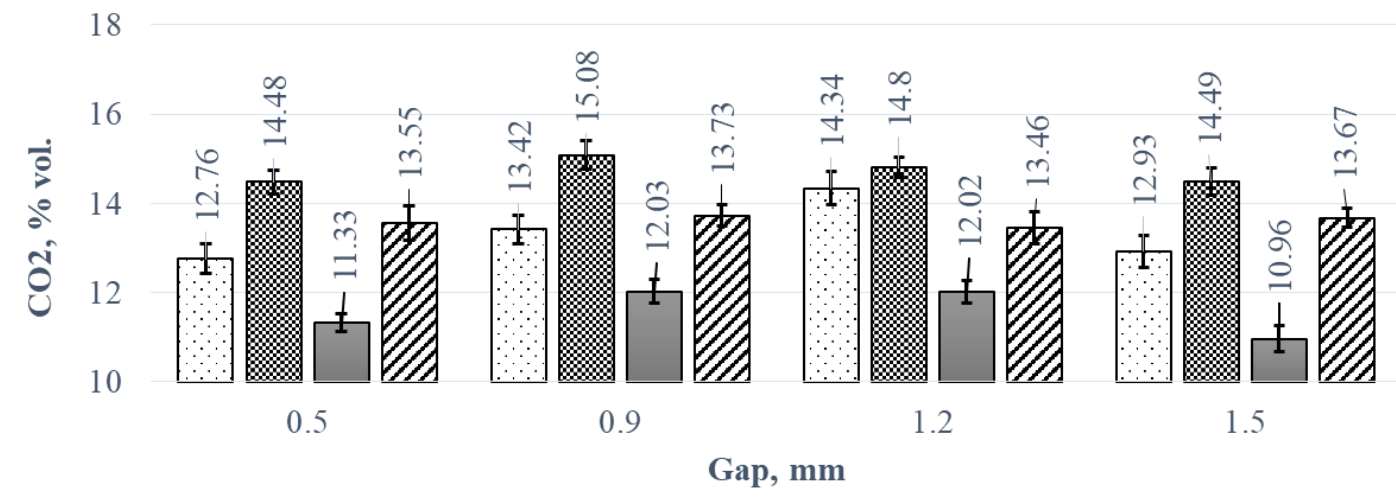

$\square$ Gasoline, $800 \mathrm{rpm} \quad$ ख Gasoline, $3000 \mathrm{rpm} \quad \square \mathrm{LPG}, 800 \mathrm{rpm} \quad \square \mathrm{LPG}, 3000 \mathrm{rpm}$

Fig. 3. $\mathrm{CO}_{2}$ changes at certain gap sizes with different fuels and speeds

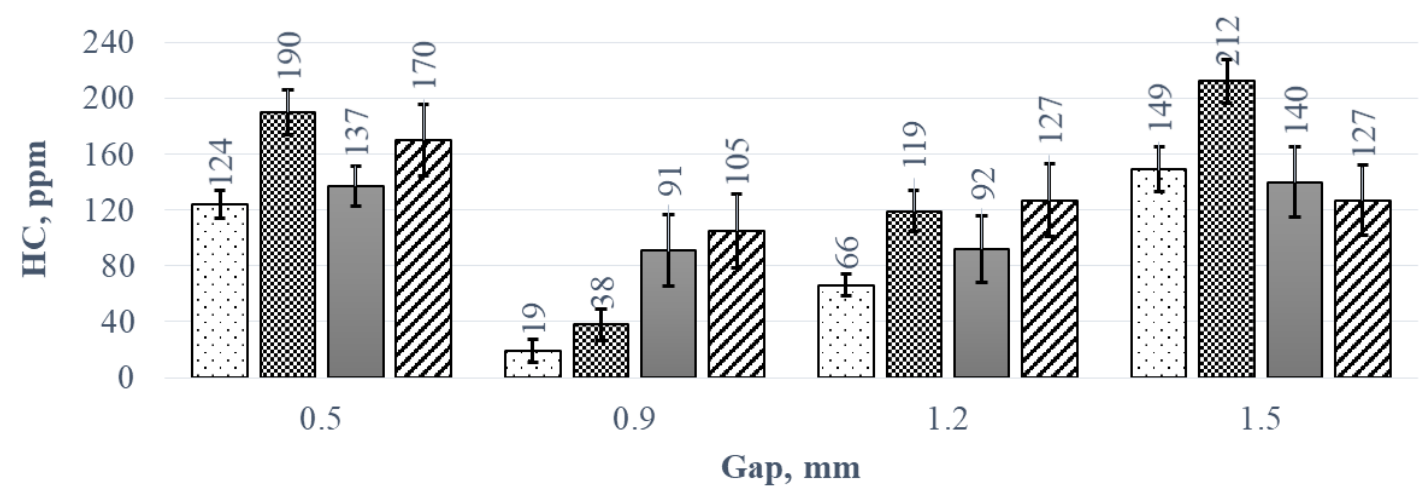

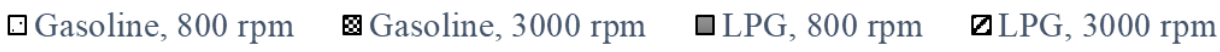

Fig. 4. HC changes at certain gap sizes with different fuels and speeds

Comparing $0.5 \mathrm{~mm}$ and $0.9 \mathrm{~mm}$ gaps, it is possible to conclude that wider gaps can reduce HC emissions based on a greater volume of air-fuel mixture exposed to the spark assisting the ignition of lean mixtures [4]. If the gap increases more than the manufacturer recommended, the opposite effect can be observed and HC emissions increase. Similar findings were observed also in another research [7], where the original plug gap demonstrated lower $\mathrm{HC}$ emissions, while a wider gap increased $\mathrm{HC}$ values.

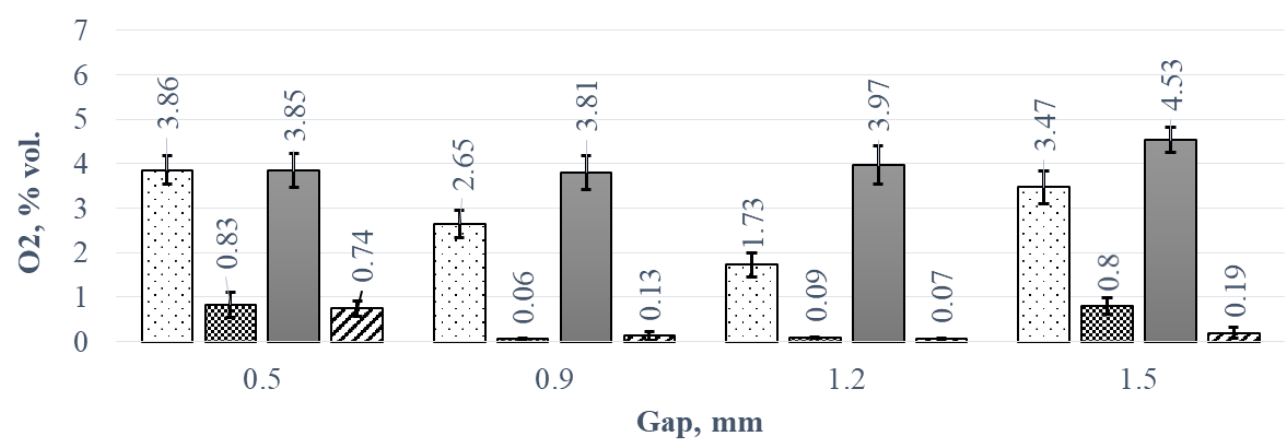

$\square$ Gasoline, $800 \mathrm{rpm}$ 囚 Gasoline, $3000 \mathrm{rpm}$ 口LPG, $800 \mathrm{rpm}$ 『LPG, $3000 \mathrm{rpm}$

Fig. 5. $\mathrm{O}_{2}$ changes at certain gap sizes with different fuels and speeds

Figure 5 shows the changes in $\mathrm{O}_{2}$. The highest values were observed for the engine running at increased idle speed $(3000 \mathrm{rpm})$ in all iterations of the experiment, but the lowest values - when the engine operated at idling, especially with an electrode gap of $0.9 \mathrm{~mm}$. During the tests with LPG at idling, the results were very low for both $0.9 \mathrm{~mm}, 1.2 \mathrm{~mm}$ and $1.5 \mathrm{~mm}$ gaps. The car manufacturer has set an $\mathrm{O}_{2}$ standard of $0.1-0.5 \%$ at idling. This norm has been achieved by running the engine with 
gasoline at the electrode spacing of $0.9 \mathrm{~mm}$ and $1.2 \mathrm{~mm}$, but with LPG at the gaps of $0.9 \mathrm{~mm}, 1.2 \mathrm{~mm}$ and $1.5 \mathrm{~mm}$.

The oxygen content of the exhaust gases is an indicator of engine performance in the lean mixture, therefore monitoring of this component in the exhaust gases allows more complete and objective diagnosis of the engine performance. Generally, high levels of oxygen in the exhaust gases indicate insufficient fuel combustion, which may be due to the intake manifold leaks, poor fuel quality, or ignition system malfunctions. At the same time, the increased amount of oxygen indicates an increase in $\mathrm{CO}$ and $\mathrm{HC}$, which was confirmed in this experiment.

\section{Conclusions}

The spark plug gap between the electrodes has a significant effect on the exhaust gas composition. According to the obtained results, it can be concluded that due to the incorrect spacing of the plug electrodes more $\mathrm{CO}$ and $\mathrm{HC}$ are formed. The highest amount of $\mathrm{CO}$ and $\mathrm{HC}$ was found, if the electrode gap of the spark plug is wider. This indicates that the gradual formation of electrode burnout, which is a normal process of spark plug wear, also changes the composition of the exhaust gases and promotes increase of them. At the same time, the variations of $\mathrm{CO}_{2}$ have been found to be insignificant, indicating that the amount of fuel burned is constant.

In general, it can be said that the variations in the gap between the spark plug electrodes must be controlled, putting attention on replacement of spark plugs after certain mileage, as the composition of the exhaust gases due to the spark plug wear has more negative effect on human health as expected. There is no such one optimal spark plug gap, but the research proved that there can be no deviations from the factory settings recommended, which is usually observed after a certain mileage.

\section{References}

[1] Birkavs A., Smigins R. 2020. Variation in diesel engine glow plug heat-up parameters depending on duration of use. Proceedings of the 24th International scientific conference "Transport means 2020", September 30 - October 02, 2020, Klaipeda, Lithuania, pp. 243-247.

[2] Bradley D., Lung F.K. Spark ignition and the early stages of turbulent flame propagation. Combust Flame, 1987, pp. 71-93. DOI: 10.1016/0010-2180(87)90022-.

[3] Birkavs A., Smigins R. An assessment of stratification of exhaust gases from gasoline and diesel engine. Agronomy Research, vol. 16(S1), 2018, pp. 977-984. DOI: 10.15159/AR.18.104

[4] Badawy T., Bao Z., Xu H. Impact of spark plug gap on flame kernel propagation and engine performance. Applied Energy, vol. 191, 2017, pp. 311-327. DOI: 10.1016/j.apenergy.2017.01.059

[5] Bhaskar H.B. Effect of spark plug gap on cycle-by-cycle fluctuations in four stroke spark ignition engine. Int. Journal of Innovative Research and Development, vol. 5(11), 2016, pp. 85-90.

[6] Bas O., Akar M.A., Serin H., Ozcanh M., Tosun E. Variation of spark plug type and spark gap with hydrogen and methanol added gasoline fuel: performance characteristics. International journal of hydrogen energy, vol. 45, 2020, pp. 26513-26521.

[7] Ozcelik Z., Gultekin N. Effect of iridium spark plug gap on emission, noise, vibration of an internal combustion engine. International Journal of Energy Applications and Technologies, vol. 6(2), 2019, pp. 44-48. DOI: 10.31593/ijeat.561307

[8] Dave D.M., Shaikh M.A. Effect of ignition parameters for enhancement of performance and emissions of a four stroke single cylinder SI engine fuelled with CNG: a technical review. International Journal of Engineering Research \& Technology, vol. 2(4), 2013, pp. 2354-2358. 